\title{
THE EFFECTS OF GREENSPACE TAX LAWS ON URBAN DEVELOPMENT
}

\author{
Roy Boyd and Geoffrey K. Turnbull*
}

\begin{abstract}
This paper provides an analysis of the effects of greenspace land taxes on the allocation of land between competing uses over time. Describing development with estimated linear equations permits the dynamic model to be used to quantify the effect of different taxes on the rate of urbanization. Using data from Forsyth County, N.C., it is shown that land taxes can slow the pace of development-as they are intended to do-but also that the efficiency gains or losses associated with the taxes are modest at best.
\end{abstract}

\section{Introduction}

The accelerated urbanization of land over the last 20 years has generated local governmental concern over the rapid loss of agricultural and forested greenspaces. As a result, communities in 47 states have enacted so-called greenspace legislation that is designed to retain land in agricultural and forest uses and to inhibit the pace of urban development. Typically, these laws involve taxing rural land at its present rather than its highest and best use, relying on differential land taxation to reduce the economic incentives of developing greenspaces. ${ }^{1}$ The design and implementation of these greenspace laws have reawakened land tax analysis to the area of public policy.

Property most commonly is appraised at the value associated with its highest and best use, and interior urban land values generally are higher than agricultural and forestland values. As time passes, the margin of land development proceeds outward from urban areas. However, local communities sometimes prefer that some open space remain within the developed area for aesthetic reasons. Furthermore, there is sympathy for current farm and forest landowners who wish that economic forces would not coerce them to change their land use patterns. Hence,

\footnotetext{
"Assistant Professor, Department of Economics, Ohio University, and Associate Professor, Department of Economics, Louisiana State University. The authors thank the USDA Forest Service for financial support, but wish to emphasize that the views expressed here are the views of the authors and not necessarily those of any government agency.
}

local governments frequently are called upon to save rural land by taxing it at its value in current use rather than its value in its highest and best use.

For quite some time economists using static analyses generally have agreed that a property tax on land or a tax on land rents is neutral with respect to alternative uses. ${ }^{2}$ Recent theoretical work by Turnbull and Boyd (1989), however, reveals that a present use tax on land rents, while not affecting the ultimate allocation of land, will affect the pace of development. Their analysis was undertaken in a multi-sector dynamic market setting, and the results were qualitative in nature.

The aim of this paper is to extend the existing literature to obtain an empirical measure of the dynamic impact of different tax regimes on land development. Because it describes development with estimated linear equations, the model permits quantification of the effect of different taxes on the rate of urban growth over time. Further, this model provides a method of calculating the economic welfare associated with any given rate of development. In this way, it also extends the suggested static welfare loss measure of Mills (1981) to a dynamic environment.

The following section presents a simple model describing the adjustment of a competitive land market to differentials in income from land in alternative uses. Next, the model is used to calculate the development rate in a county where land is taxed according to its best use. What would occur in this county under a hypothetical present-use land tax then is computed. After these calculations are made under a range of tax rates and parameter assumptions, the welfare effects of the assumed land taxes are measured. Finally, the conclusions are presented and the policy implications of the study are discussed.

\section{The Model}

The analysis follows land use theory originally set forth by von Thunen (1966) and employs a linear multi-sector dynamic market model patterned after the general formulation in Turnbull and Boyd (1989). A graphical exposition of the model and its algebraic solution are presented.

In this framework, there are three sectors within the regional economy: the urban land use sector, the nonurban land use sector, and the development or construction 
sector. The total acreage of land available in the region is $\mathrm{K}$, and the acreage used in the urban sector at time $\mathrm{t}$ is $\mathrm{k}(\mathrm{t})$. All resources are employed and competition is assumed to prevail in all relevant markets.

The land market is portrayed in the northeast panel of Figure 1 with urban land rent denoted by $r$. If the demand for urban projects is downward sloping, the urban rent is driven down as more land is developed. The urban return therefore is given by

$$
r(t)=\alpha_{0}-\alpha_{1} k(t)
$$

in the figure. The rent to land in agricultural use is assumed to be exogenous to the region and is given by $\beta_{0}$. Long run equilibrium in the land market occurs where $r=\beta_{0}$, at $\hat{k}$, and
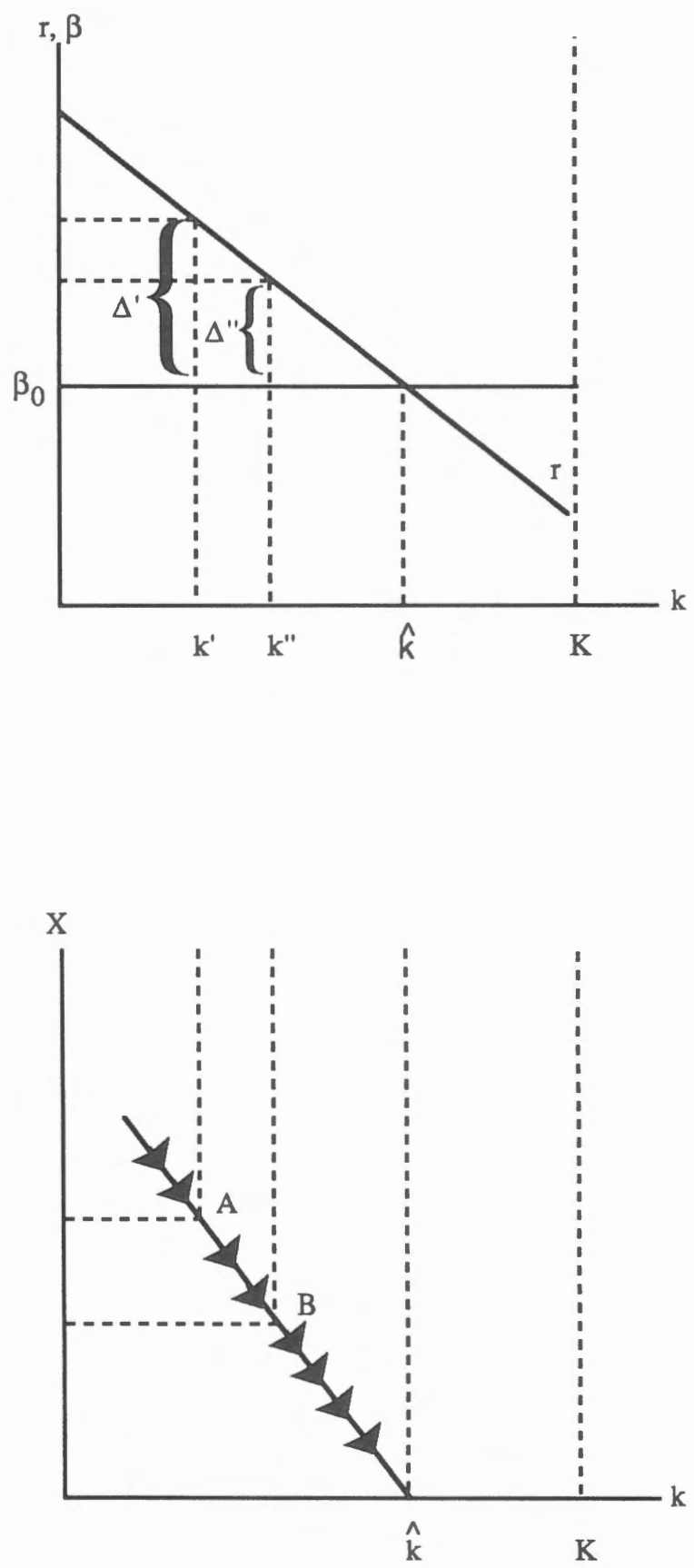

Figure 1. The Land Development Trajectory Over Time 
this corresponds to the usual static equilibrium land allocation (Mills, 1981).

Since the process of developing agricultural land for urban uses inherently is dynamic at the market level, the development sector should be incorporated into the model to make it truly dynamic. This permits examination of the time path of $k(t)$ as the land market adjusts toward a steady state equilibrium.

When agents have static expectations and base their decisions on the prevailing returns, the marginal benefit from developing land $\Delta(t)$ is the difference between the urban rent and the agricultural rent per acre:

$$
\Delta(\mathrm{t})=\mathrm{r}(\mathrm{t})-\beta_{0}
$$

Graphically, $\Delta(t)$ is the vertical distance between the urban return curve and $\beta_{0}$, as illustrated in the northeast panel of Figure 1.

At any given time t, the marginal cost, or supply price, of development is an increasing function of the new development undertaken at $t, X(t)$. This relationship is given by

$$
\mathrm{MC}=\gamma \mathrm{X}(\mathrm{t})
$$

and is depicted in the northwest panel of Figure $1 .^{3}$ The level of new development in each period is determined where marginal benefits equal marginal costs, or where

$$
\Delta(\mathrm{t})=\gamma \mathrm{X}(\mathrm{t})
$$

If, for example, the current level of urban development is given by $\mathbf{k}^{\prime}$ in Figure 1 , the marginal benefit of new development is equal to $\Delta^{\prime}$. New development will be $X^{\prime}$ where marginal costs equal $\Delta^{\prime}$.

Algebraically, the model is summarized by equations (1), (2), and (4) and the development definition

$$
\frac{\mathrm{dk}}{\mathrm{dt}}=\dot{\mathrm{k}}(\mathrm{t})=\mathrm{X}(\mathrm{t}) \text {. }
$$

To solve the model, substitute (1) and (2) into (4). This result is combined with (5) to obtain

$$
\gamma \dot{k}(t)=\alpha_{0}-\beta_{0}-\alpha_{1} k(t) .
$$

Given the initial state $k(0)$, the particular solution to the differential equation is

$$
\begin{gathered}
k(t)=\left[k(0)+\left(\beta_{0}-\alpha_{0}\right) / \alpha_{1}\right] e^{-\alpha_{1} t / \gamma} \\
+\left(\alpha_{0}-\beta_{0}\right) / \alpha_{1} .
\end{gathered}
$$

The time profile of urban land development then can be found directly from equation (7) using the appropriate values of $\alpha_{1}, \alpha_{0}, \beta_{0}$, and $\gamma$.

The nature of the land development process is depicted in the southeast quadrant of Figure 1. In this diagram, the total level of development, $\mathbf{k}$, is measured horizontally. From above, any given value of $\mathbf{k}$ determines a unique value of $X$. Hence, at k' there is X' new development at point $A$ of the arrowed development path. With this new construction the level of total development increases to k", and the rent differential is reduced to $\Delta "$. With smaller marginal benefits available, construction activity in the next period is reduced to X", and development moves toward point $B$. The process continues until, at the limit, the steady state $\hat{\mathbf{k}}$ is attained and no new development is undertaken.

\section{Development Profiles Under Best Use Assessment}

Neutrality is an important concept in the evaluation of any tax. In extending the familiar static neutrality notion to a dynamic context care must be taken to distinguish long run and short run neutrality. A long run neutral tax is one that does not alter the steady state allocation of land $\hat{k}^{4} \mathrm{~A}$ short run neutral tax, on the other hand, does not alter the intermediate path of development from that of the steady state: the arrowed development path in Figure 1 is not altered by the imposition of or change in the tax. Taxes that are neutral in both the long and short runs are termed completely neutral taxes.

The long run neutrality of a land tax based on the highest and best use of the land has been demonstrated in a number of static analyses (Mieszkowski, 1972; Oates 1969). As it turns out, this type of tax is completely neutral as well. The reasons for this are straight-forward and can be illustrated graphically. If the effective tax rate for a best use tax is $\theta$, the after-tax rental value of the land becomes $(1-\theta) r$. The urban (after tax) rent curve then rotates downward as illustrated in Figure 2. So long as the urban use of land remains the most lucrative use, the tax imposed on the land will reflect the urban value. Therefore, from 0 through $\hat{\mathbf{k}}$, all land will be taxed at the urban use level. In other words, the after-tax rents to nonurban land to the left of $\hat{\mathbf{k}}$ will rotate counter-clockwise from $\beta_{0}$ to $\beta_{0}-\theta$ r. To the right of $\hat{k}$, however, both after-tax curves will shift down by $\theta \beta_{0}$, reflecting the fact that nonurban use is in fact the best use for these acreages.

Since both urban and non-urban rent curves are reduced by equal (though varying) amounts at each level of $k$ (e.g. $\left.k^{\prime}\right)$, the corresponding values of $\Delta$ remain unchanged by the imposition of this tax. This, in turn, means that both the arrowed path of development and the location of $\hat{k}$ are the same as they were in Figure 1: A land tax based on the highest and best use of the land is completely neutral. Therefore, since development under best use taxation is identical to development in the absence of taxation, the development profiles calculated under best use taxes provide a benchmark for the analysis of other land taxes.

\section{The Area Examined}

Forsyth County, N.C., is a 412-square-mile county surrounding the central city of Winston-Salem. It is ideally 


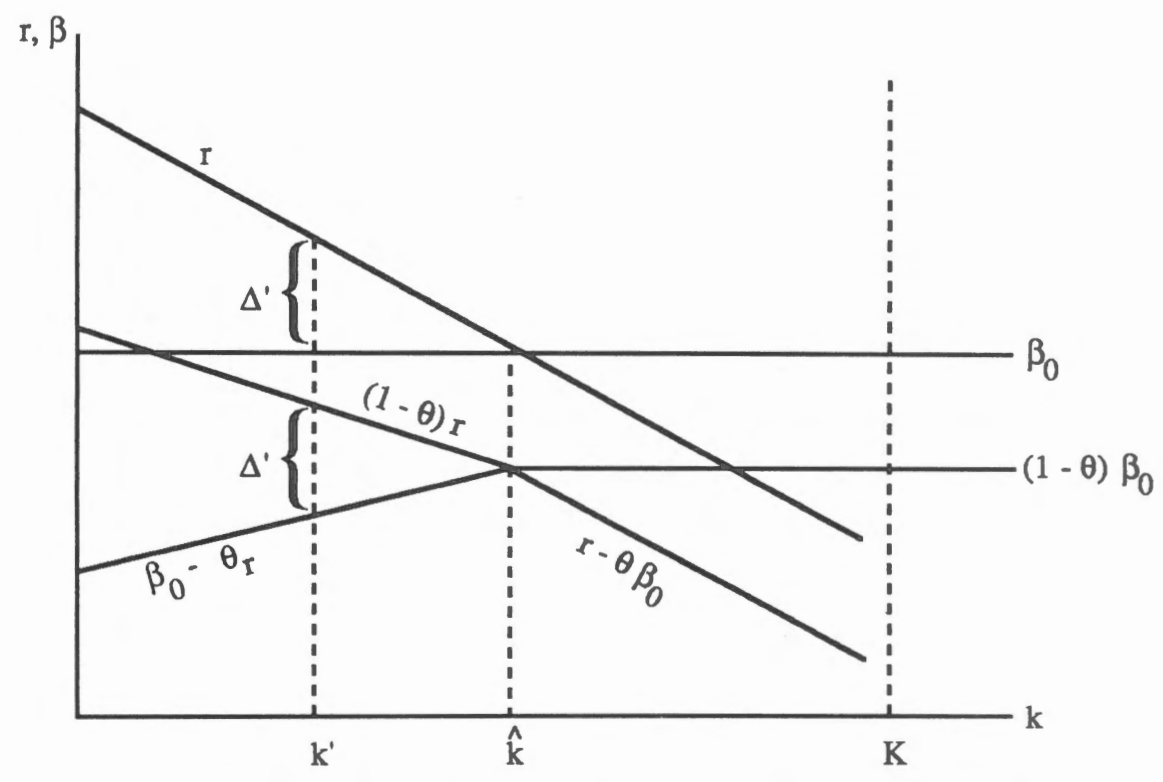

Figure 2. Land Development Effects of a Best Use Assessment Tax

suited for the purpose of this study for the following three reasons. First, there is a sufficient mix of developed and undeveloped land to insure that a solution in which $\hat{k}<\mathrm{K}$ is met. Second, the 1960-70 study period was one of negligible population growth. ${ }^{5}$ This is evidence of a relatively stable demand for land, and hence there is no need to complicate the analysis with exogenous growth considerations. Third, the 10 years of stable demand for developed land should be sufficient for the market to attain long run equilibrium. ${ }^{6}$

In 1960, Forsyth County had 220 square miles of developed land (i.e. $k(0)=220$ ). At that time, the average return per acre of undeveloped land, $\beta_{0}$, was $\$ 98.90$. $^{7}$ The return differential between undeveloped and marginal developed land, $\Delta(0)$, was approximately 10 percent, though uncertainty about the precise value led to examination of a range of differentials in the simulations below. By 1970, 52 additional square miles had been developed for urban use, and thus in the model it was assumed that $\hat{\mathbf{k}}=$ 272.

Using these rental and development values and the relationships described in equations (1) and (2), it is a relatively simple matter to compute estimates of $\alpha_{0}$ and $\alpha_{1}$. No information on the value of $\gamma$ is presently available, however, so it is calculated from the steady state condition. At $\mathrm{t}=120$, the i.e. terminal time, in months, $\mathrm{k}(120)$ is approximately $\hat{\mathbf{k}}=272$. Given this value, equation (7) is solved for a unique estimate of $\gamma$.

\section{Simulation}

In order to calculate the land development time path, the above parameter values were substituted into equation (7) and it was solved for $\mathrm{k}(\mathrm{t})$. This was repeated for each 12month interval of the 10 year period studied, and the land allocation profiles calculated for various values of $\Delta(0)$ are given in Table 1.

For larger values of $\Delta(0)$, the urban rent gradient in the northeast quadrant of Figure 1 becomes steeper. At each value of $\mathbf{k}$, more construction is undertaken and there is swifter convergence to the steady state value $\hat{\mathbf{k}}$. This is illustrated by the land use profiles in Table 1 . The empirical results also indicate, however, that the convergence paths differ less between the higher values of $\Delta(0)$ than between the lower values. Hence, the land use profile for $\Delta(0)=10$ percent is closer to that for $\Delta(0)=15$ percent than to that for $\Delta(0)=5$ percent.

To examine the sensitivity of the time paths to various $\gamma$ values, each case was calculated using a low value for $\gamma$ (one-half the estimated value), Table 2, and a high value for $\gamma$ (double the estimated value), Table 3. This provides a quantitative estimate of the response of development to rather wide variations in the marginal cost of development.

In Figure 1, an increase in the value of $\gamma$ increases the slope of the cost line in the northwest quadrant. Thus for any given value of $\Delta(t)$ less construction is undertaken, and the development path converges to $\hat{\mathbf{k}}$ at a slower rate. 
Table 1

Land Development under a Best Use Tax, Forsyth County, N.C., 1960-1970* $\gamma=36.387$

\begin{tabular}{ccccc}
\hline Time & $\Delta(0)=1 \%$ & $5 \%$ & $10 \%$ & $15 \%$ \\
\hline Month & \multicolumn{5}{c}{ Square Miles } \\
0 & 220.0000 & 220.0000 & 220.0000 & 220.0000 \\
12 & 223.1583 & 233.9864 & 244.2108 & 251.6852 \\
24 & 226.1248 & 244.2108 & 257.1493 & 264.0637 \\
36 & 228.9111 & 251.6852 & 264.0637 & 268.8995 \\
48 & 231.5282 & 257.1493 & 267.7588 & 270.7887 \\
60 & 233.9864 & 261.1436 & 269.7335 & 271.5268 \\
72 & 236.2952 & 264.0637 & 270.7887 & 271.8151 \\
84 & 238.4638 & 266.1983 & 271.3527 & 271.9278 \\
96 & 240.5007 & 267.7588 & 271.6541 & 271.9718 \\
108 & 242.4139 & 268.8995 & 271.8151 & 271.9890 \\
120 & 244.2108 & 269.7335 & 271.9012 & 271.9957 \\
Mean Absolute Error & $7.5 \%$ & $3.3 \%$ & $5.1 \%$ & $5.7 \%$ \\
\hline \hline
\end{tabular}

Land area developed, in square miles.

Table 2

Land Development under a Best Use Tax, Forsyth County, N.C., 1960-1970* $\gamma=18.1935$

\begin{tabular}{ccccc}
\hline \hline Time & $\Delta(0)=1 \%$ & $5 \%$ & $10 \%$ & $15 \%$ \\
\hline Month & \multicolumn{5}{c}{ Square Miles } \\
\multicolumn{5}{c}{. } \\
0 & 220.0000 & 220.0000 & 220.0000 & 220.0000 \\
12 & 226.1248 & 244.2108 & 257.1493 & 264.0637 \\
24 & 231.5282 & 257.1493 & 267.7588 & 270.7887 \\
36 & 236.2952 & 264.0637 & 270.7887 & 271.8151 \\
48 & 240.5007 & 267.7588 & 271.6541 & 271.9718 \\
60 & 244.2108 & 269.7335 & 271.9012 & 271.9957 \\
72 & 247.4840 & 270.7887 & 271.9718 & 271.9993 \\
84 & 250.3716 & 271.3527 & 271.9918 & 271.9999 \\
96 & 252.9191 & 271.6541 & 271.9977 & 272.0000 \\
108 & 255.1665 & 271.8151 & 271.9993 & 272.0000 \\
120 & 257.1493 & 271.9012 & 271.9998 & 272.0000 \\
Mean Absolute Error & $3.3 \%$ & $5.1 \%$ & $5.9 \%$ & $6.0 \%$ \\
\hline \hline
\end{tabular}

"Land area developed, in square miles. 
Table 3

Land Development under a Best Use Tax, Forsyth County, N.C., 1960-1970* $\gamma=72.774$

\begin{tabular}{ccccc}
\hline \hline Time & $\Delta(0)=1 \%$ & $5 \%$ & $10 \%$ & $15 \%$ \\
\hline Month & \multicolumn{4}{c}{ Square Miles } \\
0 & 220.0000 & 220.0000 & 220.0000 & 220.0000 \\
12 & 221.6039 & 227.5398 & 233.9864 & 239.4982 \\
24 & 223.1583 & 233.9864 & 244.2108 & 251.6852 \\
36 & 224.6648 & 239.4982 & 251.6852 & 259.3026 \\
48 & 226.1248 & 244.2108 & 257.1493 & 264.0637 \\
60 & 227.5398 & 248.2402 & 261.1436 & 267.0395 \\
72 & 228.9111 & 251.6852 & 264.0637 & 268.8995 \\
84 & 230.2402 & 254.6308 & 266.1983 & 270.0621 \\
96 & 231.5282 & 257.1493 & 267.7588 & 270.7887 \\
108 & 232.7765 & 259.3026 & 268.8995 & 270.2429 \\
120 & 233.9864 & 261.1436 & 269.7335 & 271.5268 \\
\hline
\end{tabular}

Land area developed, in square miles.

Though they reflect this, the land use profiles in Tables 2 and 3 reveal surprisingly small responses to rather large variations in $\gamma$.

In evaluating the relative accuracy of the various development profiles, the known intermediate land allocation $k(48)=243$ and the endpoint were used for comparison. In Table 1, the mean absolute percent error ${ }^{8}$ ranges from 3.3 percent to 7.5 percent with the lowest values where $\Delta(0)$ is in the "reasonable" range between 5 percent and 10 percent.

\section{Development Profiles Under Current Use Assessment}

As an alternative to valuing all land at its highest and best use for tax purposes, a community may elect to value land at its current use. Such policies, frequently termed greenspace laws, are intended to curb the rate of urban growth and to limit its ultimate extent. Greenspace taxes can be levied in a variety of ways, but for purposes of this analysis it was simplest to consider a proportional tax on land income.

The neutrality implications of this tax policy are demonstrated in Figure 3 . Taxing land income at a rate $\theta$ rotates the urban rent curve $r$ downward to $(1-\theta) r$ while the nonurban rent curve makes a parallel shift down to $(1-\theta) \beta_{0}$. Since the pre-tax income from all land is equal at $\hat{k}$, both curves shift downward by the same amount $\left(\theta \mathrm{r}=\theta \beta_{0}\right)$. The after-tax curves intersect at land allocation $\hat{\mathrm{k}}$, demonstrating that this tax is nuetral in the long run.
From a condition of long run equilibrium, the impact of a current use tax is somewhat different. As long as urban rents are greater than nonurban rents, urban income is decreased by a greater absolute amount than nonurban income. Hence, at land allocation k' in Figure 3 a proportional income tax will reduce the rent differential from $\Delta^{\prime}$ to $(1-\theta) \Delta^{\prime}$. This reduces the amount of construction undertaken in any given period, which, in turn, shortens the distance between $\mathbf{k}^{\prime}$ and $\mathrm{k}^{\prime}$ in Figure 1 and lengthens the time needed to reach $\hat{\mathbf{k}}$ The short run non-neutrality of greenspace taxes, then, will decrease the rate of urbanization. Because they are long run neutral, however, such taxes cannot affect the ultimate limits of urban growth.

\section{Simulation}

In order to measure the changes in the path of development resulting from the imposition of a current use tax, post-tax development profiles were calculated for the $\Delta(0)$ values used in Table 1 . In Table 4, a tax of 0.86 percent on current land use is imposed. This current use rate is equivalent to the effective best use tax rate actually imposed in Forsyth County at long run equilibrium $\mathrm{k}$. Comparing the results in Table 4 to those in Table 1 reveals that, as predicted, the current use tax retards the development rate. The magnitude of this effect, however, is quite small, and in no period does the current use tax slow development by more than 1 square mile.

The development profiles under alternative current use tax rates are presented in Tables 5 and 6 . In Table 5 the 


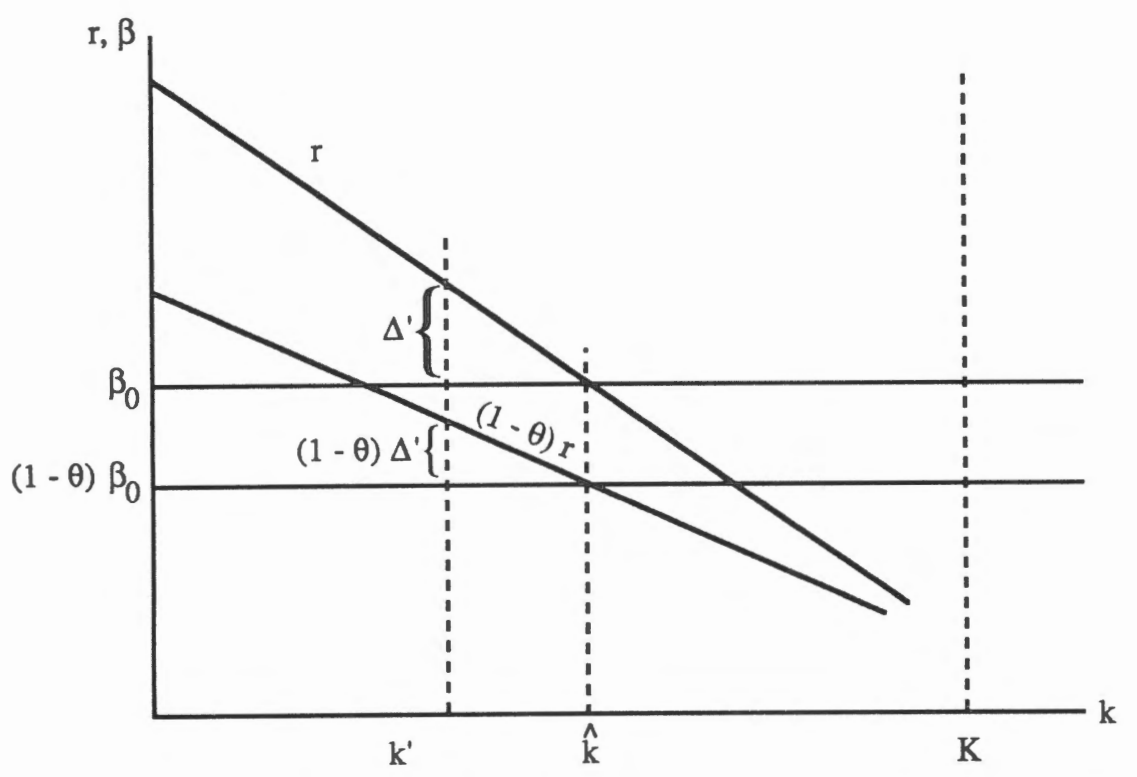

Figure 3. Land Development Effects of a Current Use Assessment Tax

original rate of 0.86 percent is halved to 0.43 percent and in Table 6 it is doubled to 1.73 percent. Not surprisingly, higher current use taxes lead to slower development. As before, however, the quantitative impact of the higher rates was quite small, even when all of these simulations were repeated under alternative values of $\gamma^{9}$. Significantly higher taxes, it would seem, will be required before existing greenspace laws have any appreciable effect on development.

\section{Measuring the Welfare Effects}

To evaluate the welfare impacts of various land taxes a dynamic analogue of the measure used by Mills [1981) for the static case was employed. In his paper, Mills measures welfare using the total area beneath the two rent curves in Figure 1 (northeast panel) and evaluates the welfare effects of land taxes from changes in those areas. The dynamic measure is similar; it is the present value of this same area,

Table 4

Land Development under a Current Use Tax, at a Rate Equivalent to the Best Use Rate, Forsyth County, N.C., 1960-1970*

\begin{tabular}{ccccc}
\hline Time & $\Delta(0)=1 \%$ & $5 \%$ & $10 \%$ & $15 \%$ \\
\hline Month & \multicolumn{4}{c}{ Square Miles } \\
0 & 220.0000 & 220.0000 & 220.0000 & 220.0000 \\
12 & 223.1353 & 233.8967 & 244.0795 & 251.5411 \\
24 & 226.0815 & 244.0795 & 257.0086 & 263.9506 \\
36 & 228.8502 & 251.5411 & 263.9506 & 268.8331 \\
48 & 231.4518 & 257.0086 & 267.6780 & 270.7540 \\
60 & 233.8967 & 261.0150 & 269.6794 & 271.5098 \\
72 & 236.1941 & 263.9506 & 270.7540 & 271.8071 \\
84 & 238.3530 & 266.1018 & 271.3310 & 271.9241 \\
96 & 240.3817 & 267.6780 & 271.6408 & 271.9701 \\
108 & 242.2881 & 268.8331 & 271.8071 & 271.9883 \\
120 & 244.0795 & 269.6794 & 271.8964 & 271.9954 \\
\hline
\end{tabular}

Land area developed, in square miles. The equivalent rate is $0.86 \%$.

See text for explanation. $\gamma=36.387$.

"Before-tax $\Delta$-values. 
Table 5

Land Development under a Current Use Tax, at a Low Tax Rate, Forsyth County, N.C., 1960-1970*

\begin{tabular}{|c|c|c|c|c|}
\hline Time & $\Delta(0)^{* *}=1 \%$ & $5 \%$ & $10 \%$ & $15 \%$ \\
\hline Month & \multicolumn{4}{|c|}{ Square Miles } \\
\hline 0 & 220.0000 & 220.0000 & 220.0000 & 220.0000 \\
\hline 12 & 223.1483 & 233.9474 & 244.1538 & 251.6226 \\
\hline 24 & 226.1060 & 244.1538 & 257.0882 & 264.0147 \\
\hline 36 & 228.8846 & 251.6226 & 264.0147 & 268.8708 \\
\hline 48 & 231.4950 & 257.0882 & 267.7238 & 270.7737 \\
\hline 60 & 233.9474 & 261.0878 & 269.7101 & 271.5195 \\
\hline 72 & 236.2512 & 264.0147 & 270.7737 & 271.8117 \\
\hline 84 & 238.4156 & 266.1565 & 271.3433 & 271.9262 \\
\hline 96 & 240.4490 & 267.7238 & 271.6484 & 271.9711 \\
\hline 108 & 242.3592 & 268.8708 & 271.8117 & 271.9887 \\
\hline 120 & 244.1538 & 269.7101 & 271.8992 & 271.9956 \\
\hline
\end{tabular}

"Land area developed, in square miles. The low tax rate is $0.43 \%$.

$\gamma=36.387$.

"Before-tax $\Delta$-values.

net of adjustment costs, as land is developed between the initial and terminal dates. ${ }^{10}$

More formally stated, the dynamic measure of economic welfare is

$$
\mathrm{W}=\int_{0}^{\mathrm{T}}\left\{\int_{0}^{\mathrm{k}(t)}\left[\alpha_{0}^{*}-\alpha_{1}^{*} \mathrm{~s}\right] \mathrm{ds}+[\mathrm{K}-\mathrm{k}(\mathrm{t})] \beta_{0}^{*}-\int_{0}^{\mathrm{k}(t)} \gamma \mathrm{sds}\right\} \mathrm{e}^{-\rho t} \mathrm{dt}(8)
$$

where the asterisks denote before-tax parameters, $k(t)$ is the relevant development time profile, and $\rho$ is the appropriate social discount rate. The first term in (8) is the area under the urban land rent curve. The second term is the rent accruing to non-urban land and the final term is the opportunity cost or value of resources expended in urban development. The relative efficiency of various land taxes is

Table 6

Land Development under a Current Use Tax, at a High Tax Rate, Forsyth County, N.C., 1960-1970*

\begin{tabular}{ccccc}
\hline & Time $\Delta(0)^{* *}=1 \%$ & $5 \%$ & $10 \%$ & $15 \%$ \\
\hline Month & \multicolumn{3}{c}{ Square Miles } \\
0 & 220.0000 & 220.0000 & 220.0000 & 220.0000 \\
12 & 223.1096 & 233.7964 & 243.9323 & 251.3791 \\
24 & 226.0332 & 243.9323 & 256.8501 & 263.8227 \\
36 & 228.7820 & 251.3791 & 263.8227 & 268.7572 \\
48 & 231.3665 & 256.8501 & 267.5862 & 270.7141 \\
60 & 233.7964 & 260.8696 & 269.6176 & 271.4901 \\
72 & 236.0809 & 263.8227 & 270.7141 & 271.7978 \\
84 & 238.2289 & 265.9922 & 271.3059 & 271.9198 \\
96 & 240.2484 & 267.5862 & 271.6253 & 271.9682 \\
108 & 242.1471 & 268.7572 & 271.7978 & 271.9874 \\
120 & 243.9323 & 269.6176 & 271.8908 & 271.9950 \\
\hline
\end{tabular}

"Land area developed, measured in square miles. The high tax rate is $1.72 \%$.

$\gamma=36.387$.

"Before-tax $\Delta$-values. 
determined by evaluating this integral and comparing the resultant $\mathrm{W}$ values for all cases considered.

As demonstrated in Turnbull and Boyd (1989), a tax on present land income may be more efficient economically than a uniform tax on highest and best use. To understand this, recall from Section II that urban development in one period lowers the rent differential $\Delta$ in subsequent periods. Under static expectations, however, developers do not recognize the marginal impact of their (collective) decisions on $\Delta$, and this leads to employment of too many resources in the development sector (compared to the socially efficient benchmark). Hence, a slower development rate would lead to an increased level of aggregate economic welfare. Since a tax on present land use slows the pace of development, such a tax also may enhance economic efficiency. On the other hand, a totally neutral tax on land's highest and best use of land will have no effect on the development rate and therefore will neither increase nor decrease welfare.

These theoretical conclusions are illustrated by the results summarized in Table 7. The welfare value, $\mathrm{W}$, associated with a tax on the highest and best land use is indeed lower than that under an equivalent tax based on present land income. Further, as was expected, the level of welfare increases as the present use tax rate rises and the development rate declines. For the case where $\Delta(0)=10$ percent (the third column in Table 7), the economic welfare associated with a best use tax is $\$ 6,809$ less than that for an equivalent rate tax on income from present land use. This welfare loss increases substantially as the value of $\Delta(0)$ is raised and it increases slightly as the value of $\gamma$ is lowered. Nowhere, however, does the loss from a best use vs. an equivalent rate present use tax exceed $\$ 13,000$, or about $5 \varnothing$ per acre (Table 8).

Overall, these results indicate that present use taxes lead to relatively insignificant efficiency gains. ${ }^{11}$ This should not be too surprising given the small variation in development time profiles across the cases examined (Tables 13). ${ }^{12}$

\section{Summary and Conclusions}

As stated at the outset, the purpose of this analysis was to quantify the effects of alternative taxes on the allocation of land among competing uses over time. It has been shown that while a tax on present use is non-neutral in the short run, appreciably, it does not slow the rate of development in most cases. The results demonstrate that under commonly held assumptions a greenspace law can lead to higher efficiency. Such gains, however, are modest at best.

The loss of agricultural and forest land to urban uses has been widely perceived as a major problem. As suggested by this analysis, however, greenspace laws seldom have proved to be an effective solution. Taxing land on the basis of its value in its present use does not affect its ultimate allocation. Furthermore, such taxation cannot slow the development process appreciably unless unrealistically high tax rates are employed. Perhaps a more effective solution would be to create greenspace zones within which development would be prohibited. Alternatively, local communities could impose variants of Vermont State Act Ten, which prohibits the sale of tracts exceeding 10 acres for purposes of further subdivision. In any case, it is clear that policy options other than differential taxation must be considered before local governments can deal adequately with the greenspace issue.

Table 7

Welfare Index Values for Alternative Land Return Differentials and Land Taxes, Forsyth County, N.C., 1960-1970*

\begin{tabular}{lcccc}
\hline \hline Tax Basics & $\Delta(0)=1 \%$ & $5 \%$ & $10 \%$ & $15 \%$ \\
\hline $\begin{array}{c}\text { Best Land Use } \\
\text { Low Rate } \\
\text { Income } \\
\begin{array}{c}\text { Equivalent } \\
\text { Rate Income }\end{array}\end{array}$ & $6,145,834$ & $5,652,090$ & $5,075,741$ & $4,521,562$ \\
$\begin{array}{c}\text { High Rate } \\
\text { Income }\end{array}$ & $6,146,141$ & $5,653,576$ & $5,078,705$ & $4,526,044$ \\
\hline
\end{tabular}

"Measure in present value dollars. These figures are for the intermediate $\gamma=36.387$. Values for high and low $\gamma$ exhibit identical patterns. 
Table 8

Welfare Cost of a Best Use Land Tax vs. an Equivalent Tax on Current Land Use, Forsyth County, N.C., 1960$1970^{*}$

\begin{tabular}{ccccc}
\hline \hline & $\Delta(0)=1 \%$ & $5 \%$ & $10 \%$ & $15 \%$ \\
\hline$\gamma=18.1935$ & 0.0038 & 0.0143 & 0.0267 & 0.0414 \\
$\gamma=36.3870$ & 0.0026 & 0.0129 & 0.0258 & 0.0390 \\
$\gamma=72.7740$ & 0.0023 & 0.0012 & 0.0235 & 0.0360 \\
\hline
\end{tabular}

Present value, dollars per acre.

Notes

${ }^{1}$ For a description of actual greenspace laws, see Dunford (1980). The concerns that have led to such laws are not new. For a historical account of such arguments in the 19th century see Hyde (1981). More recent arguments are outlined in Savage (1977).

${ }^{2}$ Notable exceptions include the works of Bentick (1979) and Mills (1981).

${ }^{3}$ See Turnbull and Boyd (1989) for the derivation of this development supply function from the underlying technology. This formulation reflects fully the opportunity cost of the resources employed in the development sector.

${ }^{4}$ Long run neutrality is parallel to the static neutrality concept.

SPopulation growth was only 0.7 percent over the decade examined. In the previous decade, however, population growth was much higher and development generally was slower. The most likely explanation for such a paradox is that consumers had to wait for growth in the local construction industry before they could exercise their pent up demand for new development. A similar pattern emerged in the Boston metropolitan area during the same time period.

${ }^{6}$ The numerical example used is a simple unchanging uniform tax with no periodic reassessment for tax purposes.

'These data come from the USDC County and City Data Book (1977). All dollar figures are in 1957 dollars.

The mean absolute percent error is defined as

$$
(1 / N) \sum_{1}^{N}\left|\left(Y_{i}^{s}-Y_{i}^{a}\right) / Y_{i}^{a}\right|
$$

where $N$ is the number of observations, $Y_{i}^{\mathbf{S}}$ is the simulated value and $\mathrm{Y}_{\mathrm{i}}^{\mathrm{a}}$ is the actual value.

The results for high and low $v$ values are available from the authors upon request.

${ }^{10}$ This measure is the objective function of the social planner in Mills $(1978,1980)$ and Tumbull and Boyd (1989), evaluated along the appropriate development time path.

${ }^{11}$ By the same token, any associated externality gains are likely to be small.

${ }^{12}$ In addition, theoretical work by Mills (1978) and Turnbull and Boyd (1989) indicates that these gains may disappear entirely under rational expectations. With rational expectations, agents foresee the precise marginal impact of their actions on the rent differential. This slows the pace of development and nullifies any potential efficiency gains from current use taxation.

\section{References}

Bentick, B. L., "The Impact of Taxation and Valuation Practices on the Timing and Efficiency of Land Use," Journal of Political Economy, 87, August 1979, 859-869.

Dunford, R. W., "A Survey of Property Tax Relief Programs for the Retention of Agriculture and Open Space Lands," Gonzaga Law Review, 115, June 1980, 675-699.

Hyde, W. F., "Volume or Value Maximization in Forestry." Annals of Regional Science, 15, 1981, 55-71.

Mieszkowski, P., "The Property Tax: An Excise or Profits Tax?" Journal of Public Economics, 1, April 1972, 73-96.

Mills, D. E., "Competition and the Residential Land Allocation Process," Quarterly Joumal of Economics, 92, May 1978, 227-244.

Mills, D. E., "Market Power and Land Development Timing," Land Economics, 56, February 1980, 10-20.

Mills, D. E., "The Non-Neutrality of Land Value Taxation," National Tax Journal, 34, March 1981, 125-129.

Oates, W. E., "The Effects of Property Taxes and Local Public Spending on Property Values: An Empirical Study of Tax Capitalism and the Tiebout Hypothesis," Joumal of Political Economy, 77, November/ December 1969, 957-971.

Savage, H., "Forest Taxation: The Power to Destroy," American Forests, 83, January 1977, 16-19.

Turnbull, G. and Boyd, R., "Dynamic Adjustment to Land Taxation Policy: Neutrality and Welfare Implications," Joumal of Environmental Economics and Management, forthcoming, 1989.

U.S. Department of Commerce, Bureau of the Census, County and City Data Book, U.S. Government Printing Office, 1977.

von Thunen, J. H., The Isolated State 1826. English edition ed. by Peter Hall, London: Pergamon Press, 1966. 